\title{
Combined Training of Plyometric-Speed for Enhancing Home First-Base Race of Baseball Players, Junior Category
}

\author{
Alexis Garcia Ponce de León ${ }^{1}$, José Enrique Carreño Vega ${ }^{2}$, Alfredo Emilio Aranda Fernández \\ ${ }^{1}$ Department of Didactics of Physical Education, Faculty of Physical Culture Sciences of the University of Matanzas, Matanzas, Cuba \\ ${ }^{2}$ Department of Sports Didactics, Faculty of Physical Culture Sciences of the University of Matanzas, Matanzas, Cuba \\ ${ }^{3}$ Baseball Academy of Matanzas, Matanzas, Cuba
}

Email address:

alexis.garcia@umcc.cu (A. G. P. de León), jose.carreno@umcc.cu (J. E. C. Vega), dichavao@icloud.com (A. E. A. Fernández)

\section{To cite this article:}

Alexis Garcia Ponce de León, José Enrique Carreño Vega, Alfredo Emilio Aranda Fernández. Combined Training of Plyometric-Speed for Enhancing Home First-Base Race of Baseball Players, Junior Category. International Journal of Sports Science and Physical Education. Vol. 4, No. 3, 2019, pp. 33-40. doi: 10.11648/j.ijsspe.20190403.11

Received: March 13, 2019; Accepted: May 6, 2019; Published: October 21, 2019

\begin{abstract}
In the last seasons the junior baseball teams of Matanzas have shown poor effectiveness in the run of the bases, having speed a determining factor in the game and therefore essential to achieve success in a baseball game. The objective of this research is to design a combined plyometric-speed training to enhance the run to first base home in baseball junior category players. To do this, a training program is applied based on the combination of plyometric and speed exercises dosed in three stages: first, general strength and low intense plyometric exercises, then, the introduction of moderate intensity plyometrics, and finally, the combined work of plyometrics of moderate-high and high intensity with speed exercises. The sample studied was composed of ten junior players, who participated in the XLVI Cuban Baseball National Championship. Three measurements were taken: first, at the end of the anatomical adaptation phase, then at the end of the muscular hypertrophy phase and the beginning of the intramuscular coordination-maximal strength combined with explosive strength and finally in the special preparation stage. To analyze the effectiveness of the exercises proposed in the time of the first home base race and in the reaction time, analysis of variance is applied, with a level of significance equal to 0.05 . It is shown that there are significant differences in the time taken in the test that included the home first base racing, between each of the moments of preparation that were made, with a decrease of $4.40 \%$. Meanwhile, in the first base home test hitting the hand with which the player batted and the moments in which controls were made influenced in the home first base time, showing a decrease of $3.38 \%$ in the effectiveness of the first base home race between the controls and a 3, 31\% in the left-handed players in relation to the right-handers. On the other hand, in the test with a medical ball of $3 \mathrm{~kg}$ with rotational movement and homefirst base race, a decrease in the time of effectiveness of $6.33 \%$ is reflected In the study, it is confirmed that there is a decrease in times with medical ball throwing $(3 \mathrm{~kg})$ with rotational movement and home first base with a decrease in the effectiveness of $3.19 \%$ between the initial and final control.
\end{abstract}

Keywords: Baseball, Plyometric, Combined Training, Speed, Home-First Base Race

\section{Introduction}

The speed as a motor ability is an essential component in both team and individual sports, and it is considered an important action in sports performance [1] Besides, as Coleman states it is also one of the five tools or physical abilities of modern baseball [2] In addition, in most of the occasions it is present in almost all decisive actions of this sport discipline, like a fielding or placing runners on base to score races [3] In the training of this motor capacity, the development of certain factors such as specific strength and techniques are crucial for obtaining maximum performance [4].

In reference to this, Vittori considers that the speed would only be a "derived capacity" of the force, while the force as "pure quality" is what determines the speed acquired by the bodies when moving [5] Calvo states that the occurrence of such effect requires a more specific physical preparation to minimize the time of each support at the moment of contact 
with the ground during the race [6] The muscles involved in this movement require great eccentric strength, allowing rapid change from eccentric to concentric contraction, and thus accelerating the body back in the required direction [7] In this regard, Bompa states that for these transformations to happen only specific training methods can be used and one of the most successful and publicized nowadays is plyometric exercises [8].

Training by practicing plyometric exercises is a very widespread method among athletes of multiple specialties, which has been studied in depth during the last decades [9] These exercises exert a positive influence on the extensor and flexor muscles of the legs achieving greater acceleration. Training should be directed in this way to accomplish the improvements that are intended [10] In this respect, JuradoLavanant et al. ensure that combinations of the plyometric jumps, with maximum actions of short duration are especially useful for baseball players [11] Chu and Myeradd state that this type of exercise allows athletes to control the body, the balance, to move quickly, and to generate great forces [12] Most of research carried out considers plyometrics a very efficient training method, as it is an element with a high degree of trainability, with the possibility of improving this motor capacity through the effect of training [13] This statement is supported by researchers who claim that the ability to produce explosive actions is important and successful, since it offers the highest possibility of transfer for its application in sport [14].

At present, training based on plyometric exercises has become an essential tool for the training of baseball players, especially when they involve explosive movements helping a player have a quick exit after making contact with the ball. At the same time, be ready to reach and steal a base, increase the power of batting or generate the tension that a pitcher needs to throw his fastball. Precisely, baseball teams of the junior category of the province of Matanzas in Cuba have been characterized, in previous years, by their positive results being among the first teams in the country. However, in recent seasons this position has been hindered by different factors, among which there is a loss of speed caused by poor effectiveness in the running of bases, resulting in a decrease in the percentage of runners on base, a problematic situation to solve. In consequence, the main scientific problem of this investigation is stated in the following question: how to boost speed in the home-first base race of baseball players, junior category? As a result, the objective of the present investigation is oriented to design a combined plyometricspeed training to boost the speed in the home-first base race of baseball players, junior category.

\section{Method}

\subsection{Sample and Methodology}

The sample under study involved ten junior players (3 lefthanded and 7 right-handed) of the first academic year, who participated in the XLVI Cuban Baseball National
Championship; all players had less than one year of experience in strength work, mainly in plyometric training, structured on the basis of Matveena planning for a single macrocycle. Sampling is intentional non-probabilistic type, representing $56 \%$ of the population, because they are still in training and have had previous experience in carrying out the exercises under study.

The research is transversal and included the preparatory period, working on the combination of different plyometric exercises for the lower limbs at different intensity according to the classification proposed by Anselmi taking into account maximum short-term actions [15] In search of greater effects that results in an increase in the speed of the home-first base race in these players, jump exercises over hurdles, simple vertical and lateral jumps, rebound with lateral fall, skipping and low, moderate and high intensity plyometrics were performed following the criteria of Meylan et al. [16] Then, moving to specific type of exercises and competition [17] Changes in speed within a similar structure can cause a higher synergic effect than would be obtained by training each one of the exercises separately [18].

For this protocol, three measurements were made: 1) at the end of the anatomical adaptation phase (coinciding with the start of the general repair phase), 2) at the end of the muscular hypertrophy phase and the beginning of intramuscular coordination-maximum strength-which is combined with explosive strength and coincides with the start of the special preparation stage and 3) in the special preparation stage, where the mixed or combined conversion phase with emphasis on power is located. It was prepared taking into consideration the postulates of the periodization of muscular strength [19].

The field tests were conducted under surface conditions similar to the competition (baseball field), following the same order in the first (pre-test), as the second and third (post-test), including (a) home first base with connection (b) home first base flyer (c) lateral throw of medicine ball with rotation and home first base race.

Home first base with connection: it was made following the protocol described by García et al.; the subject that is going to throw the ball is located towards one of the ends in front of the batter, if left or right, at a distance of 2-3 meters of the batter. The controller accompanied by a scorer to record the data in the score sheet, will be placed parallel to the first base pad in foul area to measure and record the time of the race [20] The timer will be activated when the player makes contact with the ball and will stop when the player steps on the first base [21].

In the measurement, a CASIO electronic chronometer with an accuracy of $( \pm 0.1)$ hundredth of a second was used to record the race times. A video camera Casio EX-FH20 was used, which registered at $210 \mathrm{~Hz}$, using the HUMAN software version 5.0, with highly available tools to do 2D and $3 \mathrm{D}$ studies in both kinematic and dynamic variables to know the time mediating between the contact of the bat with the ball and leaving the batter's box with the back leg [22].

Home first base flying: players made a 90-foot sprint; it 
was carried out using a CASIO electronic stopwatch with a precision of $( \pm 0.1)$ hundredth of a second, to record the times of the race.

Test of lateral launch of medicinal ball with rotation and home first base race: it was carried out following the protocol described by Spaniol, incorporating the home-first base race and using a $3 \mathrm{~kg}$ medicinal ball [23] In the measurement, a CASIO electronic chronometer with a precision of $( \pm 0.1)$ hundredth of a second was used to record the time of the race.

\subsection{Research Methods}

Different methods were applied, theoretical and empirical. The first, analytic synthetic for the foundation of the research topic, on the basis of the bibliographic analysis; the inductivedeductive provided the determination of the problem and provided the establishment of relationships between the facts that were analyzed and explanations and conclusions to which the author arrived in the present investigation; the historical-logical to verify the existence of antecedents that use this type of activities and the systemic-structuralfunctional for the elaboration of the exercises proposed. The second methods included the analysis of documents to analyze the category methods and exercises for the development of muscle strength and speed in the Comprehensive Baseball Sportsman's Preparation Program [24] The observation allowed to confirm the initial state or starting point of the players in relation to the home base first race, observing how they manifested themselves, through parameters and indicators considered in the guide made for the purpose and measurement the control and registration of the times and marks made during the home-first base race and the launch of the medicinal ball with rotational movement by the players.

\subsection{Statistical Analysis}

In the statistical examination of the data, the statistical package statgraphics plus Version 5.1 was used. To analyze the effectiveness of the proposed exercises at the time of the home first base race and the reaction time for tests 1 and 3, a unifactorial analysis of variance is applied, where the factor is the control (with three moments), while for Test 2 it is used a multifactorial analysis with two factors (controls and hand with which to hit), both analysis with a level of significance equal to 0.05 . The percent (\%) increase (Incrt) was determined, according to Brody and cited by Guzhalovskij [25] The percent was based on the following equation: $\left.\% \operatorname{Incr}=\left(\left(\mathrm{x}_{2}-\mathrm{x}_{1}\right)\right) /\left(\mathrm{X}_{2}+\mathrm{X}_{1}\right)^{*} 100\right)$

The Kolmogorov-Smirnov test was applied to determine if there were significant differences between the results obtained for tests 2 and 3 of the home first base times and the reaction time, for $95 \%$ of certainty.

Based on the results obtained from the statistical processing of the data, the authors were able to make the corresponding assessments on the state of the matter in question.

\subsection{Training}

Authors such as Sáez De Villarreal et al. have shown that plyometric training produces increases over physical performance [26] To this Gonzalez-Badillo et al, adds that it always occur when the optimal volume and frequency of training are the most appropriate [27] In this sense, Behringeret al. states that the average frequency of training is $2.7 \pm 0.8$ sessions a week on alternate days [28] In addition, García and Peña add that this frequency must guarantee the optimal natural physical development, taking into account, in addition, that the rest of the session includes training in other work directions [1]

Regarding the volume of exercises per training session, Faigenbaum et al. considers that there should be a balance for the whole body, which allows training all the large muscle groups in the same session [29] It is recommended to do 3 to 8 exercises per session according to their characteristics, the objective of training and to the level of experience accumulated in their practice. It is important to comply with the condition of maintaining a correct technical competence, during each and every one of the series and repetitions carried out, before increasing this component [30].

On the other hand, Verkhoshansky, recommends to introduce it at the end of the specific preparatory period if the "complex macrocycle" planning system is used, and at the end of the work force if a block planning system (concentrated training) is used [31] Alternatively, it is recommended at the start of the moment of development of the sport performance II if the moment-by-moment planning proposed by Reynaldo and Padilla is used [32] It must be taken into account that, if several capacities are to be worked on the same day, plyometric training will precede, as a rule, the work of strength and endurance [33] Regarding the total volume of jumps used in this protocol, the authors considered by Sáez Sáez et al. proposal which comprises a volume of 100-150 jumps per training session, achieving significant improvements in the capacity of the sprint [34].

In addition, it was considered what Meylan et al proposes in their studies the performance of plyometric exercises for the development of the power of the lower limbs [16] Meanwhile, Ortiz suggests culminating with competitive exercises, which favor an adequate transfer to specific performance, using means that allow executing the technical gesture, involving the same groups, muscle chains, range of motion [17] Lloyd et al. complements that the speeds of execution are close to those of competition [30] As another variant to this work, Reid recommends the combination of mechanically comparable plyometric and velocity exercises [35] In response to these antecedents, in this investigation, jumping exercises with hurdles, vertical simple jumps and, rebounds with fall of front and lateral fall, skipping and plyometrics of low, moderate and high intensity are applied; all of them combined with speed exercises. Below are the plyometric exercises following the criteria of López Ochoa et al. suggesting three stages in the progression of training with this method [4]. 
First stage: it consisted of starting with general strength exercises, using various exercises of multi-high and low intensity plyometrics (Figure 1) according to Bompa, dedicating $30 \%$ of the time allocated, considering heights between 0.30 and $0.40 \mathrm{~m}$, a total of 6 sets of $10-20$ repetitions are performed, the pauses between repetition of 45 to $2 \mathrm{~min}$, between series of 3 to $5 \mathrm{~min}$ [36].

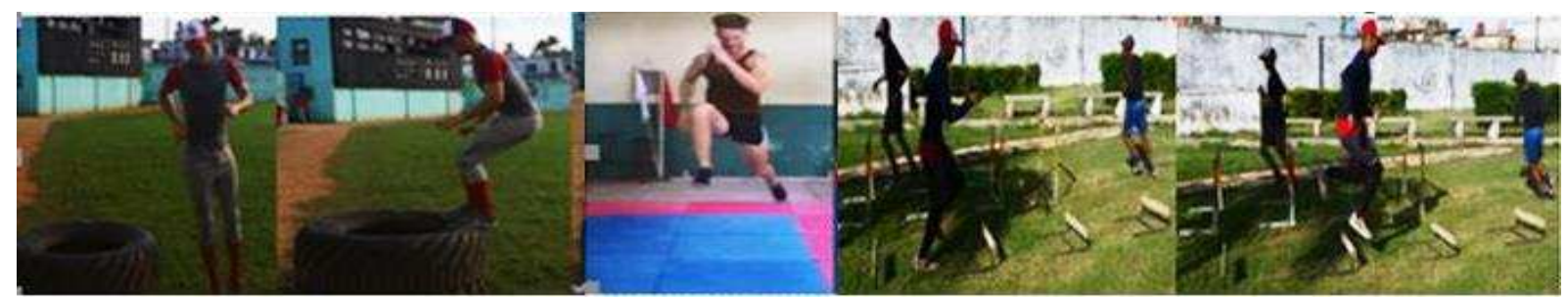

Figure 1. Sequence of exercises for the first stage: bounces with rotation of the trunk and lateral fall, simple vertical jumps with alternating legs and jumps with unilateral splint.

Second stage: it included the work of plyometrics of moderate intensity (Figure 2), dedicating $30 \%$ of the time allocated, using heights between $0.50-0.60 \mathrm{~m}$, making a total of 8 series of 10-20 repetitions, pauses between repetition $45 \mathrm{~s}-2 \mathrm{~min}$, and between series of 3-5 min.

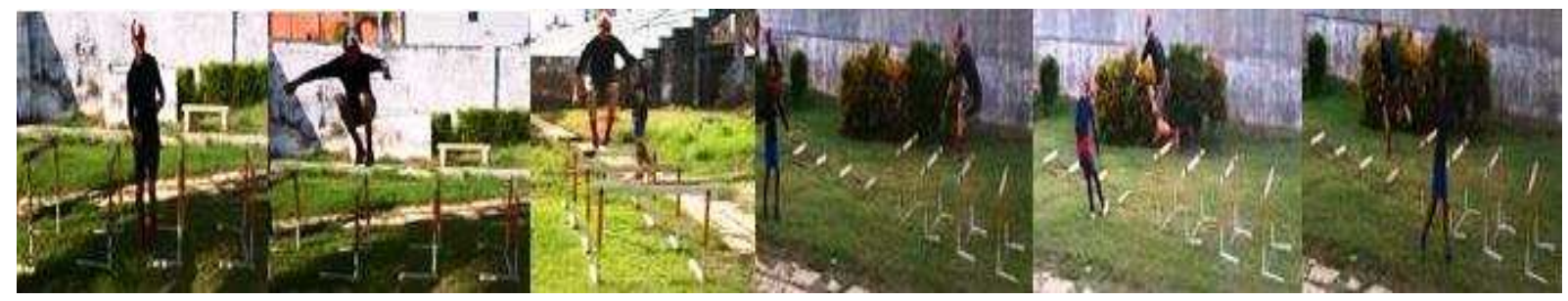

Figure 2. Sequence of exercises for the second stage: Jumps with lateral hurdles, jumps with frontal hurdles, combined exercises of jumps with bilateral hurdles and unilateral spurs.

Third stage: includes the combined work of moderate-high plyometry and high intensity with speed exercises, dedicating approximately $40 \%$ of the time allocated. At first, if you want to favor this work oriented towards maximum force, it is appropriate to use high intensity plyometrics (Figure 3), since they produce greater tension in the muscle by gathering more

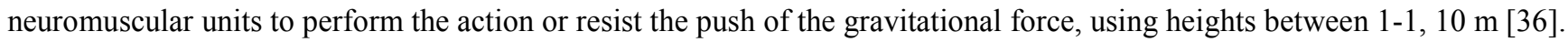

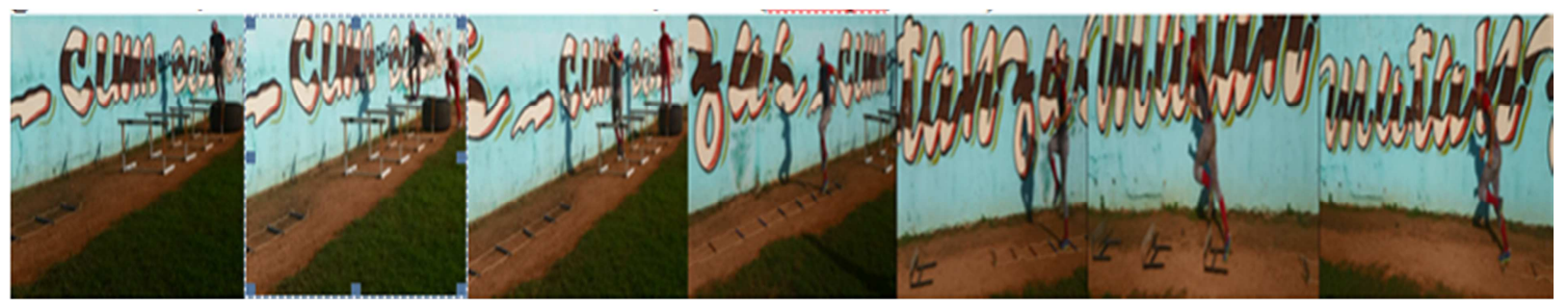

Figure 3. Exercises combined bounces with frontal fall-jumps with bilateral hurdles-skipping on the rope ladder-race with spindles-speed race.

In a second stage of the third stage, if the work oriented towards the explosive force and the reactive capacity of the neuromuscular system and considering wants to be favored, it is appropriate to use plyometrics of moderate-high intensity [37]. (Figure 4) resorting to heights between 0.70-0.75 m. In both cases, 10 obstacles at a distance of 1 meter should be used; the total distance of the exercise should not exceed the competition, performing 2-3 series of 5-7 repetitions, the pauses between repetition $45 \mathrm{~s}-2 \mathrm{~min}$, and between series of 3-5 min. It is advisable to have at least one day of rest (without plyometric work) between two consecutive sessions.

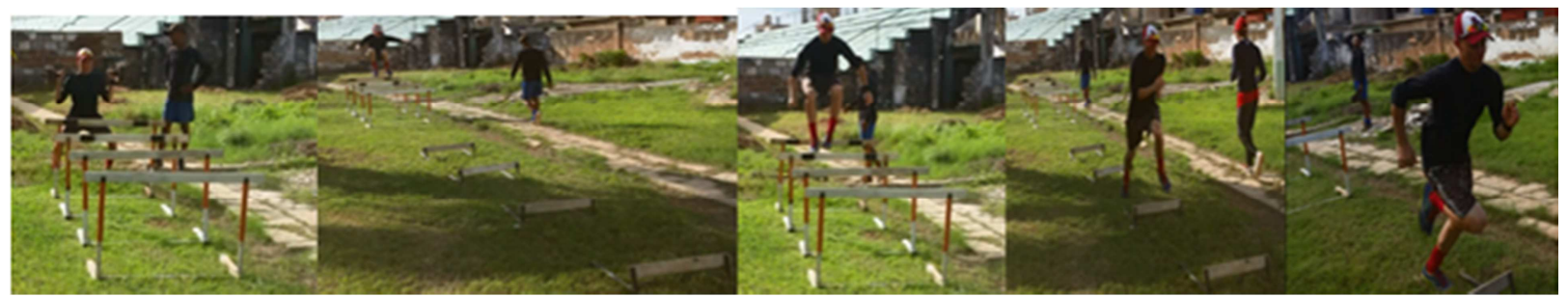

Figure 4. Combined exercises of half squat with weights- jumps with bilateral hurdles-race with spurs-speed race. 


\section{Results}

\subsection{Home First Base Flying}

When analyzing the time taken in the test that included the starting home- first base race, in each one of the moments of the preparation that were made (Figure 5) it can be seen that there are significant differences between the three controls for $95 \%$ confidence, considering that the probability value $(0.0066)$ is less than 0.05 . The reduction of the times of one control to another is observed, which becomes remarkable between the first and third control with a decrease of $4.40 \%$, which shows the effectiveness of the plyometric exercises applied.

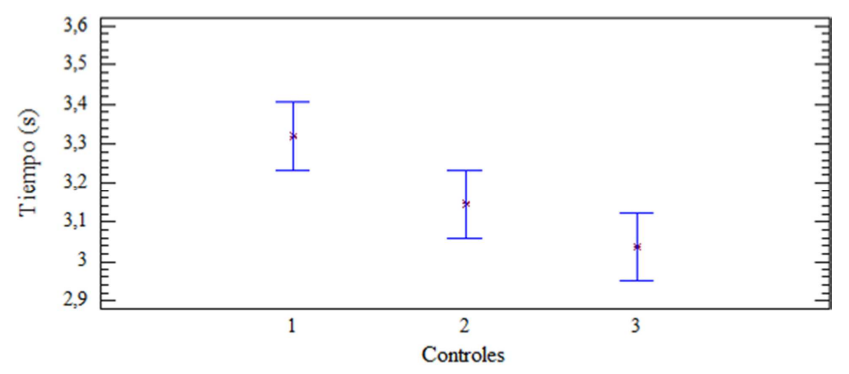

Figure 5. Confidence intervals home-first base flight.

\subsection{Home First Base with Connection}

The time between the contact of the bat with the ball and the back leg leaving the batting box shows a sustained decrease from the first to the third control, obtaining a decrease of $5.38 \%$ (Figure 6). It is notable that the effectiveness of left-handed players is significantly greater, since the probability value $(0.0000)$ is less than 0.05 , than that of right-handed players. This is reflected in a decrease of $17.24 \%$, from which it is inferred that there are significant differences in the first base home times with certain connection, with respect to the hand with which it is batted and the controls made for a $95 \%$ confidence, since probability values of 0.0001 and 0.0009 respectively are obtained. Also, a decrease of $3.38 \%$ is obtained in the effectiveness of the first home race in the third control compared to the initial and $3.31 \%$ in the left-handed players in relation to the right-handed ones.

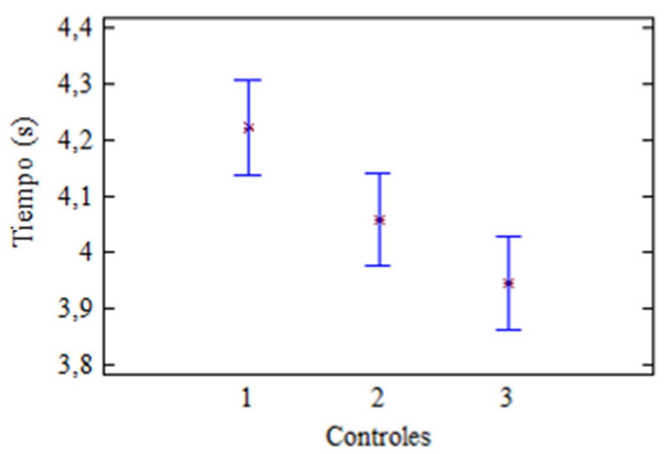

Figure 6. Confidence intervals in the home-first base race with connection between the different controls.

\subsection{Throw with $3 \mathrm{~kg}$ Medicinal Ball with Rotational Movement and Home-First Base Race}

The time between the player throwing the medicinal ball and the back leg leaving the batting box shows a decrease in the three controls performed, obtaining a decrease in the effectiveness time of $6.33 \%$ (Figure 7 ). When comparing the results obtained in this test, with respect to the first home base test with connection, using the Kolmogorov-Smirnov test, significant differences are obtained for a $95 \%$ confidence, when obtaining a probability value less than 0.05 $(0,00001)$. As seen (Figure 7), the reaction times with medicinal ball throwing exercise are approximately $0.07 \mathrm{~s}$.

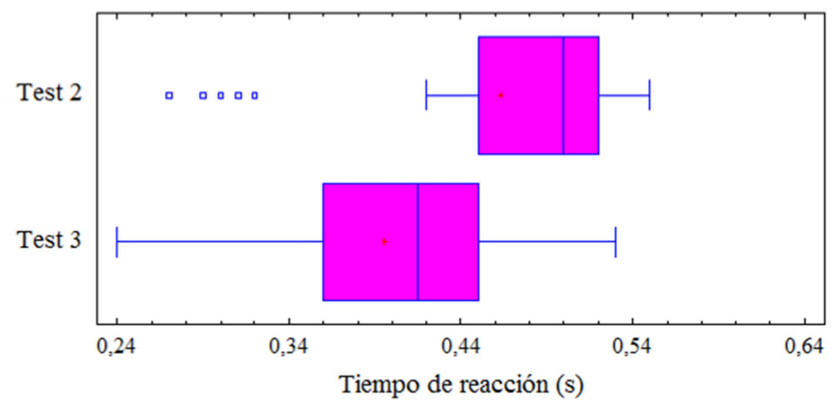

Figure 7. Behavior of reaction times for test 2 and test 3 .

It is observed that there is a decrease in times with medicinal ball throwing $(3 \mathrm{~kg})$ with rotational movement and home first base $(\mathrm{H}-1 \mathrm{~B})$ with respect to the three controls performed, with a decrease in effectiveness of $3.19 \%$ between the initial and final control (Figure 8), denoting significantly different results in the three moments with $95 \%$ confidence, since the probability value is less than 0.05 (0.0053). Regarding the results of the second and third H-1B tests, the test showed that there are no significant differences between the times for a $95 \%$ confidence, since the probability value is greater than $0.05(0.39)$.

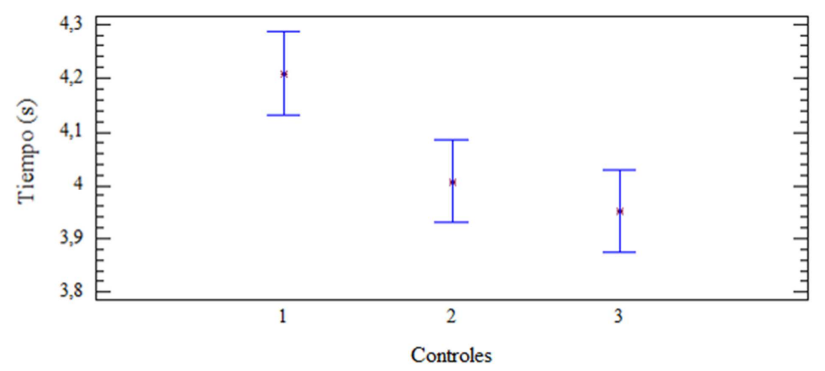

Figure 8. Release with a $3 \mathrm{~kg}$ medicine ball with rotational movement and $\mathrm{H}$ $1 B$ stroke.

\section{Discussion}

The study was designed mainly to improve important effects in the increase of the power of the lower limbs through plyometric training, based on the criteria of Chelly et al. [38] The training based on plyometrics exercises contributes to a reduction of the time of the first base home race in the baseball players, due to the efficiency in this 
transition phase, in addition to the gains obtained in the specific activities of the baseball sport. Likewise, these authors suggest that the combination of specific baseball training with plyometric exercises have contributed to the improvement of various physiological parameters, guaranteeing a better preparation to face the competition.

In response to these approaches, in this research, jumping exercises with hurdles, vertical simple jumps and bounces with fall of the front and lateral fall, skipping and plyometrics of low, moderate and high intensity were applied; all of them combined with speed exercises, following the criteria of Meylan et al. exerting positive influence to increase speed in the home-first base race in the baseball players of the Matanzas junior category during the regular season [16] These training exercises with the plyometric method were carried out in three moments or stages following the suggestions of López Ochoa et al. [4].

The increase in the speed of the home first base race obtained, agrees with the statement of Garcia et al. who assures that this is related to a significant improvement of the performance of the players, especially in the conditional field [20] In this sense, Bompa et al. states that the needs of these improvements in baseball players are diverse requiring an interconnection of the different phases of strength training and anaerobic capacities such as speed, agility and power, combined with a high capacity to make maximum efforts [19].

Results in investigations carried out by Kotzamanidis points out that the velocity in distances of 10-30 $\mathrm{m}$ can be significantly improved by the sum of the increase in explosive strength and the stretch-shortening cycle (CEA) of the muscle groups of the lower limbs [39] In addition, there is an improvement in the maximum strength, based on the assumption that the plyometric training reduces the support phase of the stride so that finally increases the speed.

In the study, a specific work was done for power training through plyometric exercises, with the aim of improving the speed of home race, which included a protocol of 20 weeks, with the combination of plyometric and speed training mechanically comparable in the same exercise, and considering in this case the position of Reid who states that the total distance of the exercise should not exceed that of competition [35] The research took into account what was raised by Lloyd et al. in terms of ensuring the safety of the players, both in the application of the loads (height, series, repetitions, breaks) and in the selection of the exercises [30].

Knowing the above criteria, it is vital to take into account that to start the training session with plyometric exercises, athletes should first warm up to reduce the risk of injury throughout the preparation, not becoming a negative factor in the expected results.

The main finding of the present study has been that the training based on plyometric exercises combined with speed exercises favor the work oriented towards the explosive force with the objective of improving the speed in the home-first base racing with baseball players. It was demonstrated that the interconnection of the different phases of strength training and the use of these exercises increase the power of the lower limbs. In the 20 microcycles where the athletes were implemented, the speed of the home-first flying base, homefirst base with connection and medicinal ball throwing $(3 \mathrm{~kg})$ with rotational movement culminating with first base home race, was significantly improved; here there is a decrease in the times of $4.40 \%, 5.38 \%$ and $3.19 \%$ respectively, demonstrating the effectiveness of the plyometric exercises applied, to reduce the times in the speed of the home-first race base in junior category baseball players.

The benefits of this study would be related to the plyometrics-oriented works, which provide a good initial acceleration. It can also be noted that in developing plyometric training the explosive force and elastic explosive force are specifically stimulated, in terms of the needs of the competition, providing players with greater explosive power that favors speed, coinciding with Hoffmanet al. [40] This conclusion allows us to infer that the results of the combined training program (plyometrics-velocity) carried out in this investigation indicate that the influence of levels of explosive force grows in relation to how fast and explosive the movements to be developed are. It should be noted that the power must be trained in such a way that there is a balance between force and speed, so when the players increase their power derived from the balance between the applied force and the speed of execution, significant improvements are obtained in their performance in the home-first base race, which was evident in the results obtained in the three tests that the authors used to measure the time of the home-first base race.

\section{Conclusions}

In the 20 microcycles where the combined plyometricsspeed training was implemented, the speed of the home-first flying base, home-first base with connection and medical ball throwing $(3 \mathrm{~kg})$ with rotational movement, culminating with race, were significantly improved. It is observed that there is a decrease in the home-first base race times of $4.40 \%, 5.38 \%$ and $3.19 \%$ respectively, demonstrating the effectiveness of the plyometric exercises applied, to decrease the times in the speed of the home-first base race in junior baseball players. In the first base home test with connection it is obtained that the hand with which it is hit also significantly influences for a $95 \%$ confidence, with a decrease of $3.31 \%$ in the effectiveness of the first base home race in the players, lefthanded in relation to right-handers. The obtaining of results with equal tendencies in the three tests (equivalent) allows assuring that the result is not influenced by the use of resources as means in the trainings with the players.

\section{References}

[1] García, F. y Peña, J. (2016). Efectos de 8 semanas de entrenamiento pliométrico y Entrenamiento resistido mediante trineo en el rendimiento de salto vertical y sprint en futbolistas amateurs. Kronos, 15 (2). 
[2] Coleman, A. E. (2000). 52-Week Baseball Training. Champaign, IL: Human Kinetics, pp. ix-xx.

[3] Martínez-Valencia, M. A. González-Ravé, J. M. Navarro, F. y Alcaraz, P. (2010). Efectos agudos del trabajo resistido mediante trineo: una revisión sistemática. Cultura, Ciencia Y Deporte, 9 (25), 35-42.

[4] López Ochoa, S.; Fernández Gonzalo R. y De Paz Fernández, J. A. (2014). Evaluación del efecto del entrenamiento pliométrico en la velocidad / Effect of plyometric training on sprint performance. Revista Internacional de Medicina y Ciencias de la Actividad Física y el Deporte vol. 14 (53) pp. 89-104.

[5] Vittori, C. (1990), "L'allenamento de lia forzanello sprint". AtletícaStudi.1-2: 3-25.

[6] Calvo, V. (2007). Entrenamiento en pista del jugador de tenis. Madrid: Set-Tenis y Pádel.

[7] García López, D.; Herrero Alonso, J. A. y De Paz Fernández, J. A. (2003). "Metodología de entrenamiento pliométrico". Revista Internacional de Medicina y Ciencias de la Actividad Física y el Deporte. 3 (12): 190-204.

[8] Bompa, T. (2005). Periodización de la fuerza. La nueva onda en Entrenamiento de la Fuerza. Grupo Sobre Entrenamiento. Primera Edición Digital.

[9] Markovic, G. y Mikulic, P. (2010). Neuro-musculoskeletal and performance adaptations to lower-extremity plyometric training. Sports Medicine. 40 (10), 859-895.

[10] Hernández, Y. H. y García, J. M. (2013). Efectos de un entrenamiento específico de potencia aplicado a futbolistas juveniles para la mejora de la velocidad con cambio de dirección. Motricidad. European Journal of Human Movement, 31, 17-36.

[11] Jurado-Lavanant, A. Fernández-García, J. Pareja-Blanco, F. y Alvero-Cruz, J. R. (2017). Efectos del entrenamiento pliométrico acuático vs. Seco sobre el salto vertical. Revista Internacional de Medicina y Ciencias de la Actividad Física y el Deporte, 17 (65), 73-84.

[12] Chu, D. A. y Myer, G. D. (2016). Pliometría. ISBN-13: 978849910533. Barcelona: Editorial Paidotribo.

[13] Flores, A. Araya, S. Guzmán, R. y Montecinos, R. (2015). Efecto de un programa de entrenamiento pliométrico sobre la biomecánica de salto en mujeres. Revista Ciencias de la Actividad Física UCM. 16 (1), 37-44.

[14] Söhnlein, Q. Müller, E. y Stöggl, T. (2014). The effect of 16week plyometric training programmes on explosive actions in early to mid-puberty elite soccer players. Journal Strength Conditining Research, 28 (8), 2105-2114.

[15] Anselmi, H. (2006). Actualización Sobre Entrenamiento de la Potencia. Argentina: Editorial Décima Edición.

[16] Meylan, C. y Malatesta, D. (2009). Effects of in-season plyometric training within soccer pracpractice. Journal Strength Conditioning Research, 23 (9), 2605-2613.

[17] Ortiz, R. H. (2004). Tenis: potencia, velocidad y movilidad. Barcelona: Inde.

[18] González-Badillo, J. J. y Ribas, J. (2002) Bases de la programación del entrenamiento de la fuerza. Barcelona: INDE.
[19] Bompa, T. y Buzzichelli, C. (2016). Periodización del entrenamiento deportivo ( $4^{\mathrm{a}}$ ed.). Barcelona: Editorial Paidotribo.

[20] García, A. Carreño, J. E. Ruiz, J. M. y García, A. (2017). El entrenamiento de fuerza para incrementar la velocidad homeprimera base en el béisbol categoría juvenil. Revista Arrancada, ISSN 1810-5882, 17 (32), 158-171.

[21] Reynaldo, F. (2017). Contratos del béisbol profesional norteamericano. Negocio o posibilidad de llegar a las grandes ligas. ISBN: 978-959-05-1038-0. Editorial Científico-Técnica. La Habana, Cuba: 124-131.

[22] Duck, T. (2011). HMA technology, the house of Hu-m-an. HUman Movement Analysis. Recuperado de http://www.hmatech.com/page01b.htm.

[23] Spaniol, F. J. (2009). Evaluación Deportiva en el Béisbol: Una Batería de Tests Específicos del Béisbol. PubliCE Standard. Pid: 1115.

[24] Federación Cubana de Béisbol (2016). Programa Integral de Preparación del Deportista de Béisbol, La Habana.

[25] Guzhalovskij, A. A. (1984). El problema de los períodos críticos de la ontogénesis y su significado para la teoría y la práctica de la educación física (pp. 211-214). En Resúmenes de teoría de la Cultura Física y Deportes. (Texto en ruso).

[26] Sáez De Villarreal, E. Requena, B. Cronin, J. (2012). The effects of plyometric training on sprint performance: a metaanalysis. J Strength Cond Res, 26 (2), 575-584.

[27] Gonzalez-Badillo, J. J. Gorostiaga, E. M. Arellano, R. y Izquierdo, M. (2005). Moderate resistance training volume produces more favorable strength gains than high or low volumes during a short-term training cycle. Journal Strength Conditioning Research, 19 (3), 689-697.

[28] Behringer M, Vom Heede A, Yue Z, Mester J. (2010). Effects of resistance training in children and adolescents: A metaanalysis Pediatrics, 126 (5): 199-210.

[29] Faigenbaum AD, Kraemer WJ, Blimkie CJ, Jeffreys I, Micheli LJ, Nitka M, et al. (2009). Youth resistance training: Updated position statement paper from the NationalStrength and Conditioning Association. J Strength Cond Res. 23 (5): S120 .

[30] Lloyd, R. S. Faigenbaum, A. D. Stone M. H. Oliver J. L. Jeffreys, I. and Moody, J. A. (2014). Position statement on youth resistance training: The 2014 International Consensus. Br J Sports Med. 48 (7): 498-505.

[31] Verkhoshansky, Y. (1967). Are depth jumps useful? Track and Field, 12 (9).

[32] Reynaldo, F. y. Padilla, O. (2007). Tendencias Actuales del entrenamiento en el béisbol. ISBN: 978-959-203-017-6. La Habana: Editorial Deportes.

[33] Yessis, M. (1993). Integrating plyometric with strength training. Fitness and Sports Review International, 28 (4): 113116.

[34] Sáez Sáez, E.; González J. J.; Izquierdo M. (2008). “Low and moderate plyometric training frequency produces greater jumping and sprinting gains compared with high frequency". Journal of Strenght and Conditioning Research. 22 (3): 715725 . 
[35] Reid, M. (2004). Complex training for tennis. ITF Coaching y sport science review, 12 (32), 6-7.

[36] Bompa, T. (2004). Entrenamiento de la potencia aplicada a los deportes. La pliometría para el desarrollo de la máxima potencia. Barcelona: Editorial Paidotribo.

[37] Verkhoshansky, Y. (2016). Todo sobre el método pliométrico. $2^{a}$ Edición ISBN: 9788480194624. Barcelona, España: Editorial Paidotribo.

[38] Chelly, M. S. Ghenem, M. A. Abid, K. Hermassi, S. Tabka, Z. y Shephard, R. J. (2010). Effects of in-season short-term plyometric training program on leg power, jump-and sprint performance of soccer players. J Strength Cond Res, 24 (10), 2670-2676.

[39] Kotzamanidis, C. (2003). "The effect of sprint training on running performance and vertical jumping in preadolescent boys". Journal of Human Movement Studies. 44: 225-240.

[40] Hoffman, J. y Helgerud, J. (2014). Entrenamiento de la Resistencia y. la Fuerza para jugadores de Fútbol. Consideraciones fisiológicas. Journal PubliCE Standar. 